\title{
Necrotizing Pancreatitis: Current Management and Therapies
}

\author{
Christine Boumitri ${ }^{1}$, Elizabeth Brown ${ }^{2}$ and Michel Kahaleh ${ }^{2}$ \\ Division of Gastroenterology and Hepatology, Department of Medicine, ${ }^{1}$ University of Missouri, Columbia, MO, ${ }^{2}$ Weill Cornell Medicine, New \\ York, NY, USA
}

Acute necrotizing pancreatitis accounts for $10 \%$ of acute pancreatitis (AP) cases and is associated with a higher mortality and morbidity. Necrosis within the first 4 weeks of disease onset is defined as an acute necrotic collection (ANC), while walled off pancreatic necrosis (WOPN) develops after 4 weeks of disease onset. An infected or symptomatic WOPN requires drainage. The management of pancreatic necrosis has shifted away from open necrosectomy, as it is associated with a high morbidity, to less invasive techniques. In this review, we summarize the current management and therapies for acute necrotizing pancreatitis. Clin Endosc 2017;50:357-365

Key Words: Walled-off pancreatic necrosis; Pseudocyst; Pancreatitis; Necrosis

\section{INTRODUCTION}

Acute pancreatitis (AP) is the twelfth most common gastrointestinal presentation to the emergency department (ED) in the United States. ${ }^{1}$ The number of ED visits with AP has increased by $12 \%$ since 2006 with a $0.5 \%$ mortality rate. ${ }^{1} \mathrm{AP}$ can be mild, moderate, or severe. While mild pancreatitis is commonly self-limited, severe pancreatitis can be associated with the development of complications such as parenchymal/ peripancreatic fluid collections and necrosis (Fig. 1). Severe AP is defined by single or multiple organ failure lasting more than 48 hours, and is associated with a mortality rate as high as $25 \%{ }^{2,3}$ Acute necrotizing pancreatitis is diagnosed when more than $30 \%$ of the gland is affected by necrosis and accounts for $5 \%$ to $10 \%$ of pancreatitis cases. ${ }^{2}$ The Revised Atlanta classification is used to classify pancreatic fluid collections that develop following AP. ${ }^{2}$ When fluid collections arise within 4 weeks of the diagnosis of pancreatitis and are with-

Received: November 9, 2016 Revised: February 10, 2017

Accepted: February 22, 2017

Correspondence: Michel Kahaleh

Division of Gastroenterology and Hepatology, Department of Medicine, Weill Cornell Medicine, 1305 York Avenue, 4th Floor, New York, NY 10021, USA Tel: +1-646-962-4000, Fax: +1-646-962-0110, E-mail: mkahaleh@gmail.com

(cc) This is an Open Access article distributed under the terms of the Creative Commons Attribution Non-Commercial License (http://creativecommons.org/ licenses/by-nc/3.0) which permits unrestricted non-commercial use, distribution, and reproduction in any medium, provided the original work is properly cited. out any solid or nonliquefied components, they are referred to as acute pancreatic fluid collections (APFCs). When fluid collections arise from necrotizing pancreatitis and contain both fluid and necrotic material, they are referred to as acute necrotic collections (ANCs). After 4 weeks of diagnosis an APFC may develop into a pancreatic pseudocyst (PP) with a well-defined enhancing wall. Walled off pancreatic necrosis (WOPN) results when the ANC matures and develops a wall after 4 weeks. These collections can be present within the pancreatic parenchyma, adjacent to it, or both; they can be sterile or infected. ${ }^{4}$ While sterile necrosis is associated with $5 \%$ to $10 \%$ mortality rate, the mortality rate increases to $20 \%-30 \%$ when necrosis becomes infected. ${ }^{5-7}$ Thus, early recognition and institution of appropriate therapy is necessary.

In the setting of necrotizing pancreatitis, the necrosis most commonly involves both pancreatic and peripancreatic fat tissue $(75 \%-80 \%)$. In some instances, the necrosis can be limited to the pancreas alone (5\%) or to the peripancreatic fat alone $(20 \%){ }^{8}$ Isolated peripancreatic necrosis carries a better prognosis when compared to pancreatic parenchymal necro$\operatorname{sis}^{9,10}$ An early contrast-enhanced computed tomography (CT) may fail to reveal necrosis within the first few days, however, a contrast enhanced CT after the first week revealing non-enhancing pancreatic parenchyma is considered to be pancreatic necrosis. A WOPN can be asymptomatic or symptomatic, sterile or infected. The diagnosis of the latter is crucial for early institution of antibiotics and further interventions as 
needed. CT findings suggestive of an infection include the presence of extra-luminal gas, but some clinicians believe that a definitive diagnosis can only be confirmed when a percutaneous image guided or endoscopic ultrasound (EUS)-guided fine needle aspiration (FNA) is positive for bacterial/fungal stain or culture. ${ }^{11} \mathrm{~A}$ recent Asian consensus statement on endoscopic management of walled-off necrosis refuted the concept that an image guided FNA is indispensable for the diagnosis of infected walled off necrosis. ${ }^{12}$ No predisposing factors have been validated to increase the risk of development of pancreatic necrosis, however, the most common etiology of necrotizing pancreatitis is gallstones $(40 \%-48 \%)$, followed by alcohol consumption $(24 \%-27 \%){ }^{12,13}$

\section{NECROTIZING PANCREATITIS: MANAGEMENT AND TREATMENT}

The initial assessment of AP should involve determining disease severity and whether signs of organ failure are present. This acuity will dictate admission to the regular floor versus an intensive care unit. A patient with AP should undergo a workup for the etiology of pancreatitis with attention to any signs of biliary obstruction and or cholangitis that might warrant an urgent endoscopic retrograde cholangiopancreatography (ERCP).

The first step in management of AP is aggressive intravenous fluid hydration to maintain intravascular volume, as well as pancreatic and systemic perfusion. Antibiotics have no prophylactic role in preventing infection and failed to show benefit in sterile pancreatic necrosis. ${ }^{14}$ Their use is thus reserved to patients with highly suspected or confirmed infected pancreatic necrosis. Providing adequate nutritional support is a crucial component in treating patients with necrotizing pancreatitis. Patients are usually kept nil per os (NPO) with early feeding if pancreatitis is mild and oral intake can be tolerated. Patients with more severe disease have been traditionally kept NPO for concerns of inducing pancreatic enzymes, further aggravating inflammation. However, we have learned that the increased catabolic state associated with severe pancreatitis and the lack of nutritional support are associated with high mortality. ${ }^{15}$

\section{Nutritional support and enteral feeding}

Total parenteral nutrition (TPN) was the standard of care for patients with severe AP, however enteral nutrition beyond the ligament of Treitz was found to be more beneficial. A large Cochrane meta-analysis revealed that enteral nutrition was superior to TPN in severe AP with reduction in infectious complications, length of hospital stay, and overall mortality. ${ }^{16}$
Therefore enteral nutrition is preferred over TPN with early institution of feeding (within 48 hours) preferred over late, however the exact timing remains debatable. ${ }^{17}$

According to the guidelines of American Society for Parenteral and Enteral Nutrition (ASPEN), European Society for Parenteral and Enteral Nutrition (ESPEN) and American college of Gastroenterology (ACG), early institution of continuous enteral nutrition in patients with severe pancreatitis improves outcomes and decreases infectious complications. ${ }^{18-20}$ Early enteral nutrition can moderate the excessive immune response during the early stage of severe $\mathrm{AP}^{21}$ The concept of pancreatic rest have rendered naso-jejunal feeds the preferred modality, however nasogastric feeds have been shown to be non-inferior and safe. ${ }^{22}$ A randomized controlled trial comparing nasogastric to nasojejunal feeds is currently under study. ${ }^{23}$ A new randomized controlled trial comparing enteral nutrition to nil per mouth in patients hospitalized for AP showed that early enteral nutrition had no significant reduction in persistent organ failure or mortality when compared to the no nutritional support group. ${ }^{24}$ However, in this trial, patients with local or systemic complications were classified as a subgroup and not included in the severe acute pancreatitis group (SAP) according to the Revised Atlanta classification. The inclusion of this subgroup in the SAP might be the reason why enteral nutrition was beneficial in the previous studies. Therefore, further studies are needed to determine whether this will change the management of patients with severe AP.

Few studies have been published in regards to the optimal enteral nutrition formula, including elemental (monomeric), semi-elemental (oligomeric), or polymeric. ${ }^{25-27}$ Although elemental and semi-elemental formulas cost about $400 \%$ more than polymeric formulas, they are still used because they are believed to cause less exocrine pancreatic stimulation in patients with pancreatitis because of their low fat content, and the presence of free amino acids instead of intact proteins which bind to free trypsin in the gut. ${ }^{28,29}$ In their meta-analysis, Petrov et al. concluded that polymeric formula, compared with semi-elemental formulation, is not associated with a higher risk of feeding intolerance, infectious complications, or death in AP patients. ${ }^{30}$

The addition of supplements to enteral nutrition such as arginine, glutamine, $\omega-3$ polyunsaturated fatty acids, and prebiotics is not recommended despite few studies showing positive impact on outcome. ${ }^{31-37}$ Studies on the addition of probiotics to enteral nutrition to decrease infectious complications have been contradictory and the benefits of probiotics remain controversial. The combination of enteral nutrition and probiotics, also called eco-immunonutrition, showed reduction in inflammatory markers when compared to enteral nutrition alone. ${ }^{38}$ However, other studies have showed increased mor- 
tality with the use of probiotics and thus their use in patients with severe AP is not routinely recommended. ${ }^{39,40}$

\section{Approaches to drainage of necrotic collections}

Two thirds of necrotic pancreatic collections are sterile and will resolve with conservative management, while the remainder will become infected and will require further intervention. ${ }^{41}$ Thus, the most important factor to guide further interventions is the presence of symptoms or infected necrosis. Indications for intervention in each stage of the necrotic collection are as follows:

- A sterile ANC with presence of symptoms, such as abdominal pain or mechanical obstruction: intervention should be delayed preferably for 4 weeks or longer. ${ }^{42}$

- An infected pancreatic fluid collection: dictate drainage, endoscopic drainage should be preferred over radiology whenever possible due to better drainage and decreased risk of percutaneous fistula, and over surgery because of high morbidity and mortality. ${ }^{42}$

- An asymptomatic WOPN and a sterile ANC do not require intervention regardless of size, because these may resolve spontaneously over time. ${ }^{42}$

The three well established approaches for drainage are surgical, radiological, and endoscopic. Over the last two decades the paradigm has shifted away from surgical intervention to radiology and finally endoscopy with an emphasis on less invasive approaches.

\section{Surgical}

Open necrosectomy used to be the standard approach for treating infected pancreatic necrosis. This approach is associated with high morbidity and mortality rates (up to $95 \%$ and $25 \%$, respectively), as well as debilitating complications such as entero-cutaneous and pancreatico-cutaneous fistula formation. ${ }^{43,44}$ With the development of minimally invasive surgery, minimally invasive pancreatic surgeries have evolved and laparoscopic approaches to treat pancreatic necrosis have proved efficacy with a survival rate as high as $85 \%{ }^{45,46}$ The laparoscopic approach is associated with a lower incidence of new onset organ failure post-operatively when compared to the open approach. ${ }^{47,48}$ The currently used technique is laparoscopic necrosectomy, using a retrogastric transmesocolic or retroperitoneal approach to the lesser sac. ${ }^{49}$ Another alternative after the placement of the percutaneous drain would be a videoscopic-assisted retroperitoneal debridement (VARD), where a small $5 \mathrm{~cm}$ subcostal incision is made to allow larger pieces of solid debris to be removed. The PANTER trial assigned patients with pancreatic necrosis and infected necrosis to either primary open necrosectomy or a step up approach, where a percutaneous drain was initially placed followed by minimally invasive retroperitoneal necrosectomy when needed. It showed that a minimally invasive step up approach was associated with a lower rate of major complications and death when compared to open necrosectomy. ${ }^{50}$ The step up approach has proven its efficacy since most necrotic collections are percutaneously accessible and large pieces of necrosis can be removed; however, there is risk of developing a chronic pancreatico-cutaneous fistula with this approach. ${ }^{51}$

\section{Percutaneous}

The percutaneous approach can be used as a primary therapy or as an adjunct therapy for endoscopic or surgical drainage. The percutaneous drain is placed using ultrasound (US) guidance with fluoroscopy or CT guidance. Access using the retroperitoneal approach is preferable to the transperitoneal approach with fewer complications. It also facilitates the step up approach. A 12 French drain is left in place and irrigated three times a day with sterile water. The drain can be upsized if needed. A systematic review showed that percutaneous approach alone was successful in $55.7 \%$ of patients without need for another surgical intervention, with a mortality of $15.4 \%$ in cases of infected necrosis. ${ }^{52}$ The PANTER trial showed that percutaneous drainage without subsequent necrosectomy was achieved in only $30 \%$ of cases..$^{50}$ In another study, the percutaneous approach using the step up approach achieved only $25 \%$ resolution of WOPN when compared to direct endoscopic necrosectomy (DEN), with $92 \%$ resolution rate. ${ }^{53}$ Ideally, any intervention should be delayed to allow for better demarcation and liquefaction of the necrosis after the onset of disease (usually after 4 weeks). However, a recent study showed better outcomes with less organ failure and in-hospital mortality when percutaneous drainage is performed early in the course of necrotizing pancreatitis. ${ }^{42,54}$ In their systematic research on timing of catheter drainage in patients with infected necrotizing pancreatitis, van Grinsven et al. showed no relation between the timing of intervention and mortality or length of hospital stay, though one study revealed a lower rate of pancreatic endocrine insufficiency and a higher rate of pancreatic exocrine insufficiency with early drainage. ${ }^{51,55} \mathrm{An}$ international consensus on the timing of intervention with percutaneous drainage does not exist yet and practice among experts varies. The POINTER trial, a randomized controlled trial by the Dutch Pancreatitis Study Group is currently ongoing and aims to compare immediate and delayed catheter drainage in an attempt to further improve the outcome of these severely ill patients. ${ }^{56}$

\section{Endoscopic}

When the endoscopic approach is used, the necrotic collection is punctured through the gastric or enteric wall under 


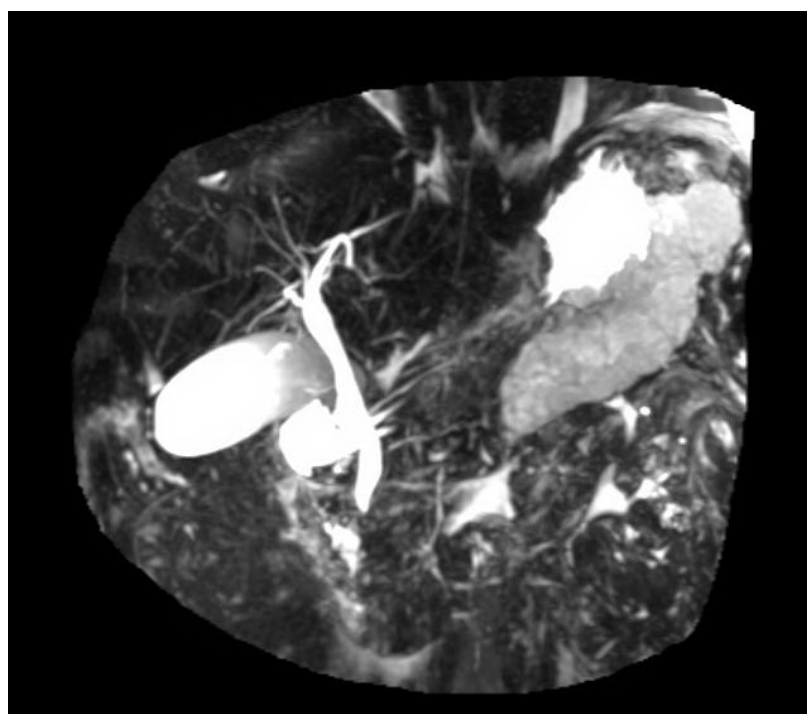

Fig. 1. Large retrogastric pancreatic fluid collection on magnetic resonance imaging.

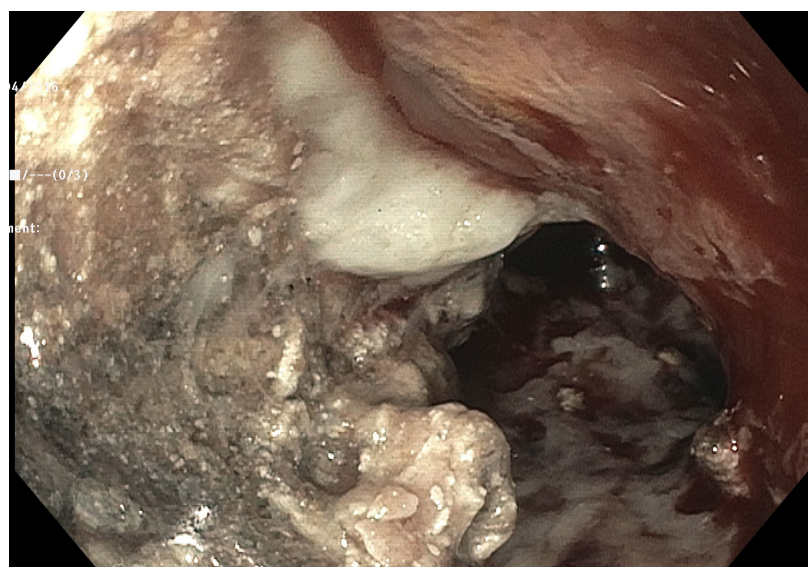

Fig. 2. Large necrotic debris visualized during endoscopic necrosectomy.

US guidance. An FNA needle or needle knife can be used as an initial puncture device. The tract is then dilated and stented. The first endoscopic approach to treat necrosis was described by Baron et al. in $1996 .^{57}$ Before the introduction of metallic stents, the procedure involved placement of plastic stents with irrigation using a nasocystic drain without mechanical debridement of the necrotic cavity. The success rate was estimated at $81 \%$ using this technique. ${ }^{57}$ Seewald et al. then introduced the concept of mechanical debridement via tract dilation and insertion of the scope into the tract (Fig. 2). ${ }^{58}$ The success was higher with a $91 \%$ resolution rate. Since then, multiple studies and trials have proved the efficacy of this approach. Mechanical debridement can be performed using a snare, net or basket. DEN can be performed from a single site with some studies revealing that the use of multiple sites for drainage can improve success rate. ${ }^{59-61}$ Hydrogen peroxide used during necrosectomy was also evaluated in retrospec-

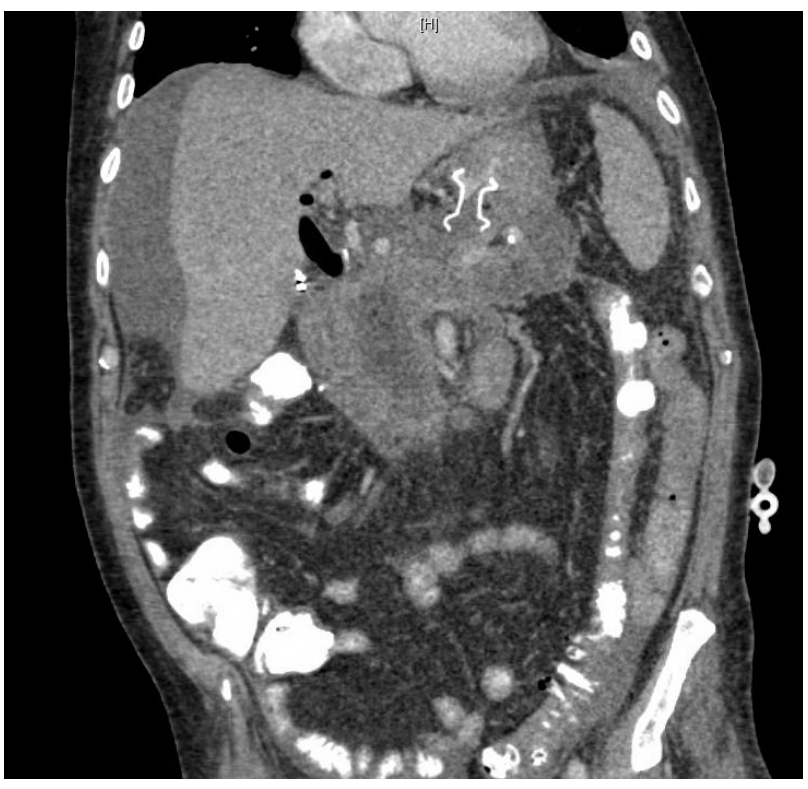

Fig. 3. Computed tomography (CT) image of abdomen showing a transgastric lumen apposing metal stent placed into a walled off necrosis (patient A).

tive studies and was shown to be effective in reducing the number of sessions and the need for external irrigation. ${ }^{62,63}$ The endoscopic approach can be used as a primary treatment for WOPN or as a step up approach after percutaneous drainage. The TENSION trial will compare a surgical step up approach versus an endoscopic step up approach. ${ }^{64}$ However, the pilot PENGUIN trial showed that DEN is associated with a reduction in pro-inflammatory response, namely serum interleukin-6 levels, and lower rates of pancreatic fistulas and new-onset multi-organ failure when compared to minimally invasive surgical necrosectomy. ${ }^{65}$ Throughout the years and with advances in technology, multiple metallic stents have emerged and have been used in DEN. ${ }^{66-71}$ The recent development of large lumen-apposing metal stents (LAMS) has led to a shift in paradigm, creating a real transluminal conduit permitted DEN. ${ }^{71,72}$ Similar to the treatment of pancreatic fluid collections, it is always important to determine the integrity of the pancreatic duct (PD) since $\mathrm{PD}$ disruptions are associated with worse outcomes. ${ }^{73}$

\section{Fully covered self-expandable metallic stents}

The first metallic stents that were used for pancreatic necrosectomy were biliary fully covered self-expandable metallic stents (FCSEMS), which provided a larger diameter for drainage when compared to plastic stents; however, these did not allow the passage of an endoscope for debridement. ${ }^{74}$ On the other hand, esophageal FCSEMS have a larger lumen allowing for mechanical debridement using the endoscope with reported resolution rate ranging between $88 \%$ and $90 \%$ in small single center studies. ${ }^{69,75}$ Both biliary and esophageal FCSEMS 


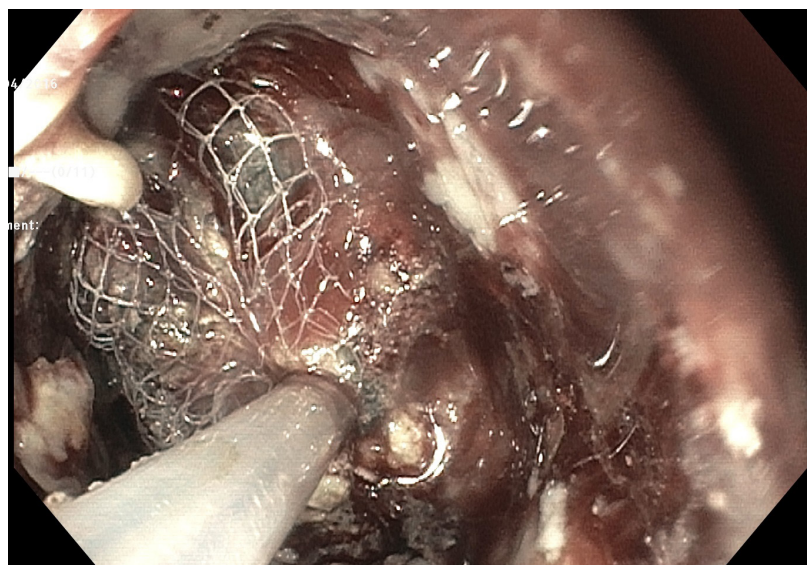

Fig. 4. Endoscopic view of removal of necrosis though the lumen apposing metal stent.

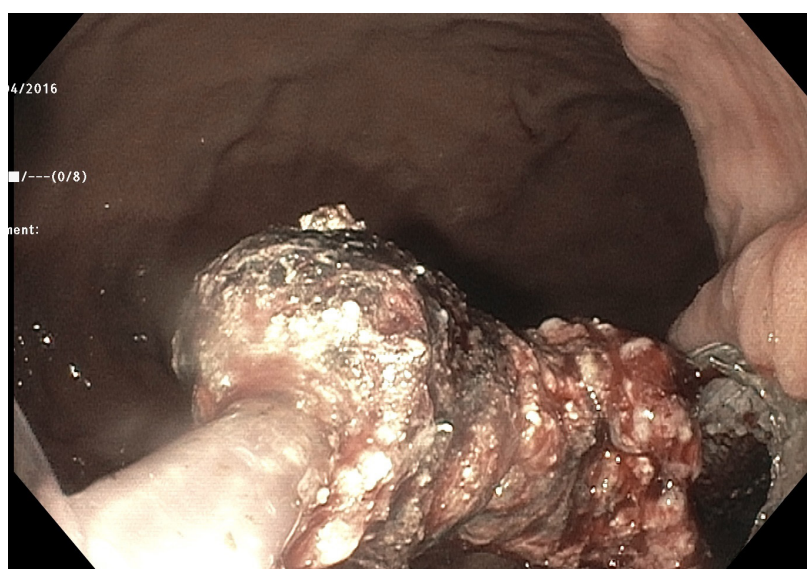

Fig. 5. Endoscopic view of the extraction of necrosis from the necrotic cavity with deposition into the stomach.

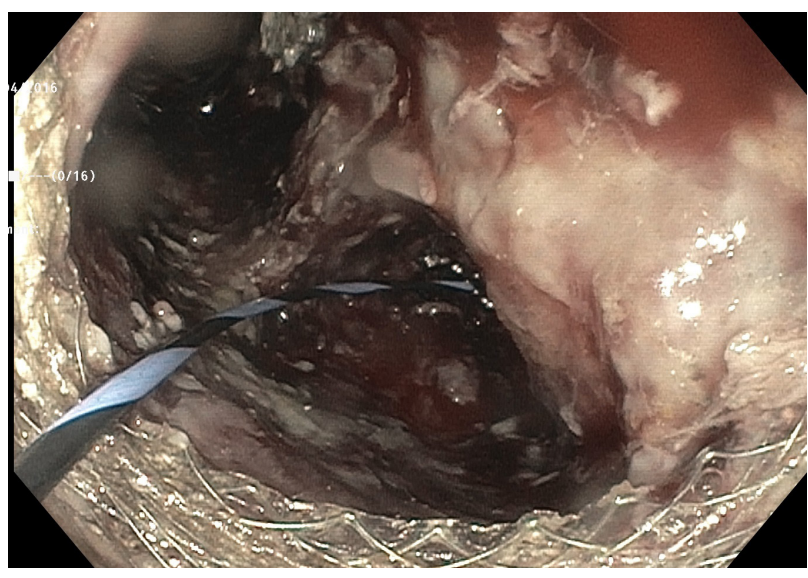

Fig. 6. Endoscopic vision of a necrotic cavity post debridement.

carry a risk of migration.

\section{Lumen-apposing metal stents}

LAMS were developed with the aim of reducing the rate of migration and have a dog bone shape with double-flange,

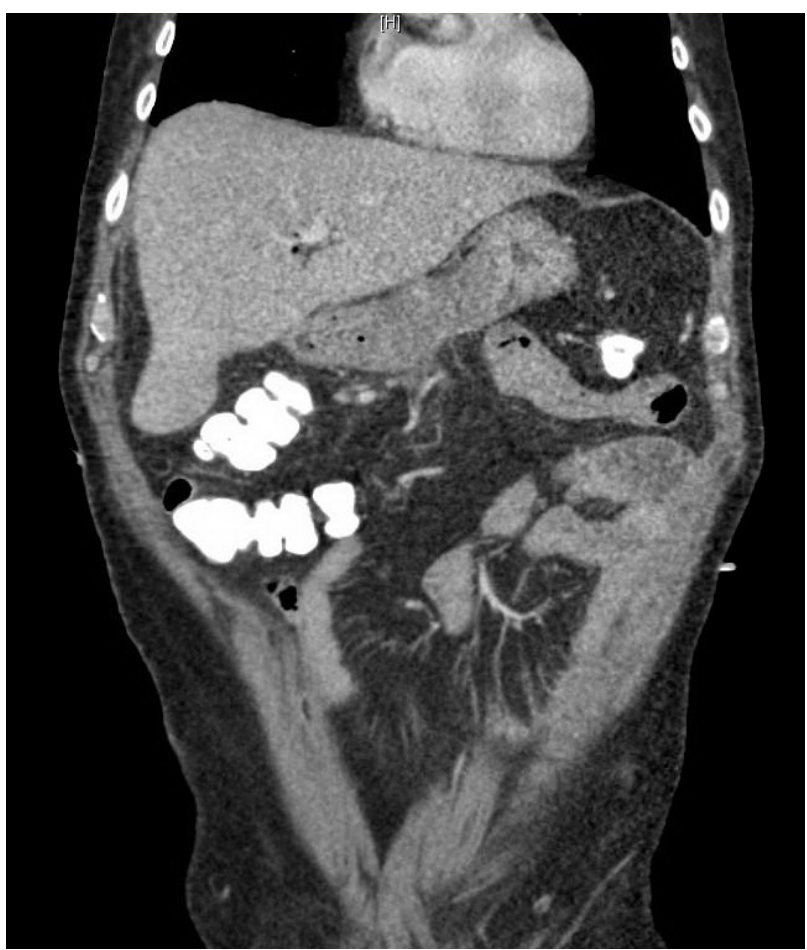

Fig. 7. Computed tomography (CT) image of abdomen showing resolution of walled off necrosis (patient $A$ ).

allowing apposition of the walls of the cavity and enteric wall (Fig. 3). Its wide diameter enables the passage of an endoscope for necrosectomy. It has proven its efficacy in draining pancreatic fluid collections. Its role in pancreatic necrosis is not well defined and limited to a small number of studies. ${ }^{76}$ A recent retrospective multicenter case series by Sharaiha et al. in which 124 patients with WOPN underwent endoscopic transmural drainage using LAMS revealed a technical success of $100 \%$ and a clinical success rate of $86.3 \%$ at 3 months follow up (Figs. 4-7). ${ }^{71}$ The stents remained patent in $94 \%$ of patients with a migration rate of $5.6 \%$.The median number of endoscopic interventions was 2 (Fig. 8). LAMS definitely offer a promising future for DEN. A LAMS mounted on a cautery tipped delivery system, AXIOS-EC (Boston Scientific, Natick, MA, USA), has also been demonstrated to have a high success rate $(92.5 \%)$ in draining pancreatic fluid collection including WOPN. $^{77}$

\section{Pancreatic duct exploration}

The main pancreatic duct (MPD) can be affected in necrotizing pancreatitis and partial or complete disruption of the MPD must be recognized and addressed. In a recent retrospective study analyzing factors and outcomes associated with MPD disruption in patients with acute necrotizing pancreatitis, PD disruption was estimated to occur in up to $38 \%$ of cases. Extensive necrosis, refractory pancreatic fluid collections, 


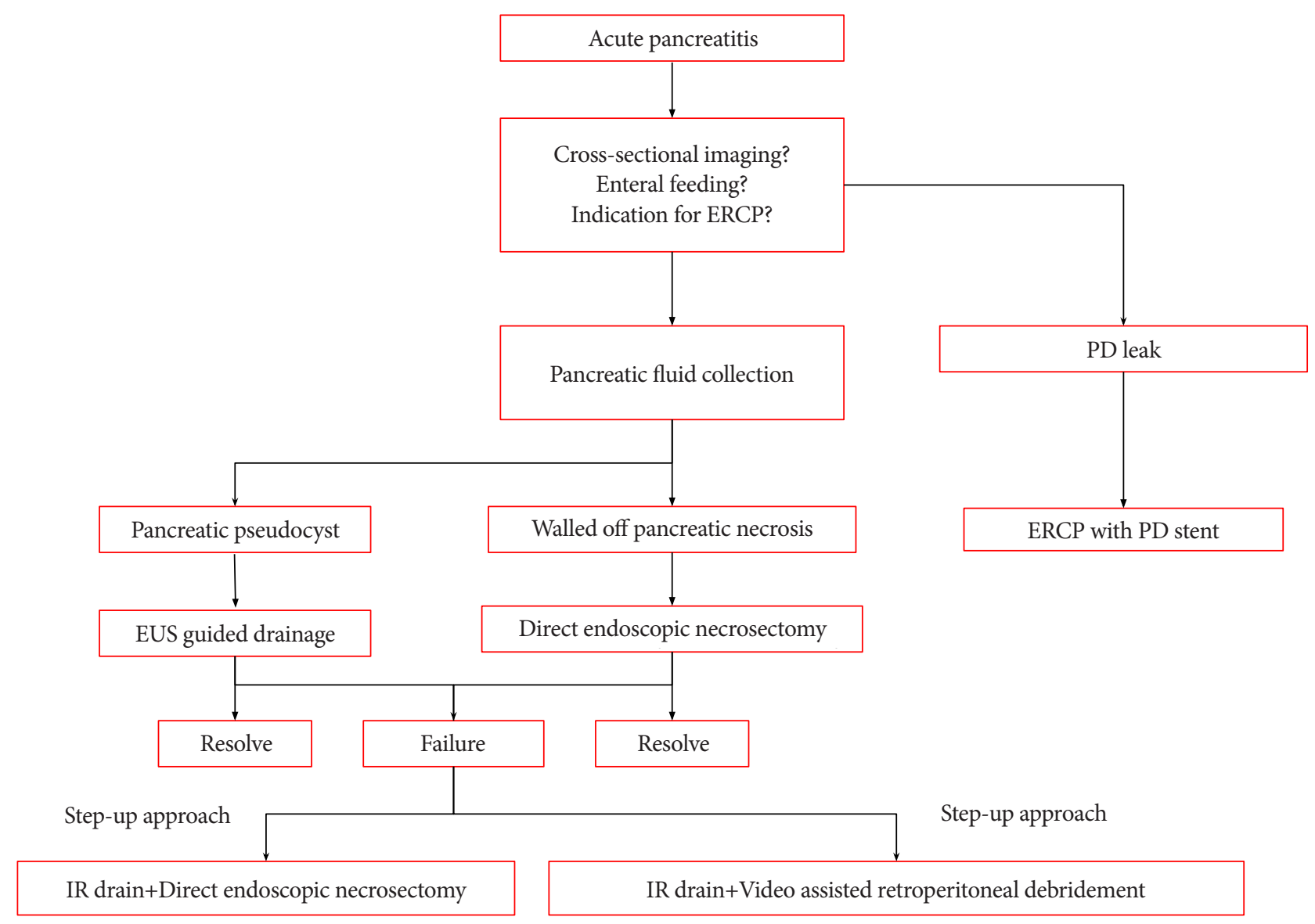

Fig. 8. Management algorithm of pancreatic fluid collection. ERCP, endoscopic retrograde cholangiopancreatography; PD, pancreatic duct; EUS, endoscopic ultrasound.

persistence of amylase-rich output from percutaneous drainage, and amylase-rich ascites/pleural effusion were associated with MPD disruption. ${ }^{78}$ Other retrospective studies have also shown that PD disruption is associated with severe pancreatitis and pancreatic necrosis. ${ }^{73,79}$ Patients with disrupted duct are also at higher risk of recurrent pancreatitis. ${ }^{80,81}$ Early recognition of MPD disruption is necessary since it is not only associated with worse outcomes but also prolonged hospital stay. ${ }^{78}$ According to Jang et al., complete MPD disruption is associated with a lower success rate of endoscopic transpapillary stenting and a higher frequency of surgical treatment when compared to partial MPD disruption. ${ }^{78}$ Ductal imaging using magnetic resonance cholangiopancreatography (MRCP) or ERCP is an important step in managing patients with necrotizing pancreatitis. Although no guidelines exist about the regular use of ERCP in patients with necrotizing pancreatitis to diagnose PD disruption, the procedure should be tailored to patients who carry the above-mentioned risk factors, namely recurrent pancreatitis and persistent collections. Jang et al. also found that MRCP is a good non-invasive tool to assess PD with a sensitivity of $80 \%$ when compared to
ERCP. $^{78}$ Others report a lower sensitivity with MRCP since small ductal disruptions can be missed. To overcome this limitation, secretin stimulation before MRCP can increase the sensitivity of detecting PD disruptions. ${ }^{82}$

\section{CONCLUSIONS}

Acute necrotizing pancreatitis carries a high rate of morbidity and mortality. Early recognition and close monitoring of affected patients is crucial. Treatment consists of aggressive intravenous fluid resuscitation, pain control, and institution of enteral nutrition as early as possible. While sterile necrosis might resolve with above conservative measures, infected necrosis requires further intervention. The collection is classified according to the Revised Atlanta classification. ANC corresponds to collections that are less than 4 weeks old without a capsule, while WOPN are encapsulated collections. Indications for drainage or necrosectomy of these collections include suspected infection or symptomatic collection. Initially, the most widely used approach to infected necrosis has been 
open surgical necrosectomy, however treatment has evolved and shifted towards minimally invasive techniques such as percutaneous drainage, minimally invasive surgeries, and finally endoscopic necrosectomy. Endoscopic necrosectomy offers the advantage of internal drainage, avoiding both surgical procedures (associated with high morbidity) and external drainage (with possible fistulae).

\section{Conflicts of Interest}

The authors have no financial conflicts of interest.

\section{REFERENCES}

1. Peery AF, Crockett SD, Barritt AS, et al. Burden of gastrointestinal, liver, and pancreatic diseases in the United States. Gastroenterology 2015;149:1731-1741.e3.

2. Banks PA, Bollen TL, Dervenis C, et al. Classification of acute pancreatitis--2012: revision of the Atlanta classification and definitions by international consensus. Gut 2013;62:102-111.

3. Mofidi R, Duff MD, Wigmore SJ, Madhavan KK, Garden OJ, Parks RW. Association between early systemic inflammatory response, severity of multiorgan dysfunction and death in acute pancreatitis. Br J Surg 2006;93:738-744.

4. Adler DG, Baron TH, Davila RE, et al. ASGE guideline: the role of ERCP in diseases of the biliary tract and the pancreas. Gastrointest Endosc 2005;62:1-8.

5. Dervenis C, Johnson CD, Bassi C, et al. Diagnosis, objective assessment of severity, and management of acute pancreatitis. Santorini consensus conference. Int J Pancreatol 1999;25:195-210.

6. Beger HG, Rau B, Isenmann R. Natural history of necrotizing pancreatitis. Pancreatology 2003;3:93-101.

7. Werge M, Novovic S, Schmidt PN, Gluud LL. Infection increases mortality in necrotizing pancreatitis: a systematic review and meta-analysis. Pancreatology 2016;16:698-707.

8. Sakorafas GH, Tsiotos GG, Sarr MG. Extrapancreatic necrotizing pancreatitis with viable pancreas: a previously under-appreciated entity. J Am Coll Surg 1999;188:643-648.

9. Bruennler T, Hamer OW, Lang S, et al. Outcome in a large unselected series of patients with acute pancreatitis. Hepatogastroenterology 2009;56:871-876

10. Ashley SW, Perez A, Pierce EA, et al. Necrotizing pancreatitis: contemporary analysis of 99 consecutive cases. Ann Surg 2001;234:572-579; discussion 579-580.

11. Banks PA, Gerzof SG, Langevin RE, Silverman SG, Sica GT, Hughes MD. CT-guided aspiration of suspected pancreatic infection: bacteriology and clinical outcome. Int J Pancreatol 1995;18:265-270.

12. Isayama $H$, Nakai $Y$, Rerknimitr $R$, et al. Asian consensus statements on endoscopic management of walled-off necrosis Part 1: epidemiology, diagnosis, and treatment. J Gastroenterol Hepatol 2016;31:1546-1554.

13. van Santvoort HC, Bakker OJ, Bollen TL, et al. A conservative and minimally invasive approach to necrotizing pancreatitis improves outcome. Gastroenterology 2011;141:1254-1263.

14. Wittau M, Mayer B, Scheele J, Henne-Bruns D, Dellinger EP, Isenmann R. Systematic review and meta-analysis of antibiotic prophylaxis in severe acute pancreatitis. Scand J Gastroenterol 2011;46:261-270.

15. Goodgame JT, Fischer JE. Parenteral nutrition in the treatment of acute pancreatitis: effect on complications and mortality. Ann Surg 1977;186:651-658.

16. Al-Omran M, Albalawi ZH, Tashkandi MF, Al-Ansary LA. Enteral versus parenteral nutrition for acute pancreatitis. Cochrane Database Syst Rev 2010;(1):CD002837.
17. Li JY, Yu T, Chen GC, et al. Enteral nutrition within 48 hours of admission improves clinical outcomes of acute pancreatitis by reducing complications: a meta-analysis. PLoS One 2013;8:e64926.

18. Meier R, Ockenga J, Pertkiewicz M, et al. ESPEN guidelines on enteral nutrition: pancreas. Clin Nutr 2006;25:275-284.

19. Tenner S, Baillie J, DeWitt J, Vege SS; American College of Gastroenterology. American college of gastroenterology guideline: management of acute pancreatitis. Am J Gastroenterol 2013;108:1400-1415; 1416.

20. McClave SA, Martindale RG, Vanek VW, et al. Guidelines for the provision and assessment of nutrition support therapy in the adult critically Ill patient: society of critical care medicine (SCCM) and American society for parenteral and enteral nutrition (A.S.P.E.N.). JPEN J Parenter Enteral Nutr 2009;33:277-316.

21. Sun JK, Mu XW, Li WQ, Tong ZH, Li J, Zheng SY. Effects of early enteral nutrition on immune function of severe acute pancreatitis patients. World J Gastroenterol 2013;19:917-922.

22. Jiang K, Chen XZ, Xia Q, Tang WF, Wang L. Early nasogastric enteral nutrition for severe acute pancreatitis: a systematic review. World J Gastroenterol 2007;13:5253-5260.

23. Whitcomb D. Study of nutrition in acute pancreatitis (SNAP) [Internet]. Bethesda (MD): ClinicalTrials.gov; c2007 [updated 2016 Jan 26; cited 2016 Oct 20] Available from: https://clinicaltrials.gov/ ct2/show/NCT00580749?term=nasojejunal+or+nasogastric+feeds+in+acute+pancreatitis\&rank=1.

24. Stimac D, Poropat G, Hauser G, et al. Early nasojejunal tube feeding versus nil-by-mouth in acute pancreatitis: a randomized clinical trial. Pancreatology 2016;16:523-528.

25. Pupelis G, Selga G, Austrums E, Kaminski A. Jejunal feeding, even when instituted late, improves outcomes in patients with severe pancreatitis and peritonitis. Nutrition 2001;17:91-94.

26. Makola D, Krenitsky J, Parrish C, et al. Efficacy of enteral nutrition for the treatment of pancreatitis using standard enteral formula. Am J Gastroenterol 2006;101:2347-2355.

27. Tiengou LE, Gloro R, Pouzoulet J, et al. Semi-elemental formula or polymeric formula: is there a better choice for enteral nutrition in acute pancreatitis? Randomized comparative study. JPEN J Parenter Enteral Nutr 2006;30:1-5.

28. Erskine JM, Lingard CD, Sontag MK, Accurso FJ. Enteral nutrition for patients with cystic fibrosis: comparison of a semi-elemental and nonelemental formula. J Pediatr 1998;132:265-269.

29. Spanier BW, Bruno MJ, Mathus-Vliegen EM. Enteral nutrition and acute pancreatitis: a review. Gastroenterol Res Pract 2011;2011.

30. Petrov MS, Loveday BP, Pylypchuk RD, Mcllroy K, Phillips AR, Windsor JA. Systematic review and meta-analysis of enteral nutrition formulations in acute pancreatitis. Br J Surg 2009;96:1243-1252.

31. Thomson A. Nutritional support in acute pancreatitis. Curr Opin Clin Nutr Metab Care 2008;11:261-266.

32. Marik PE. What is the best way to feed patients with pancreatitis? Curr Opin Crit Care 2009;15:131-138.

33. Karakan T, Ergun M, Dogan I, Cindoruk M, Unal S. Comparison of early enteral nutrition in severe acute pancreatitis with prebiotic fiber supplementation versus standard enteral solution: a prospective randomized double-blind study. World J Gastroenterol 2007;13:2733-2737.

34. Hallay J, Kovács G, Szatmári K, et al. Early jejunal nutrition and changes in the immunological parameters of patients with acute pancreatitis. Hepatogastroenterology 2001;48:1488-1492.

35. Pearce CB, Sadek SA, Walters AM, et al. A double-blind, randomised, controlled trial to study the effects of an enteral feed supplemented with glutamine, arginine, and omega- 3 fatty acid in predicted acute severe pancreatitis. JOP 2006;7:361-371.

36. Lasztity N, Hamvas J, Biró L, et al. Effect of enterally administered n-3 polyunsaturated fatty acids in acute pancreatitis--a prospective randomized clinical trial. Clin Nutr 2005;24:198-205.

37. Lodewijkx PJ, Besselink MG, Witteman BJ, et al. Nutrition in acute pancreatitis: a critical review. Expert Rev Gastroenterol Hepatol 2016;10:571- 
580.

38. Wang G, Wen J, Xu L, et al. Effect of enteral nutrition and ecoimmunonutrition on bacterial translocation and cytokine production in patients with severe acute pancreatitis. J Surg Res 2013;183:592-597.

39. McClave SA, Heyland DK, Wischmeyer PE. Comment on: probiotic prophylaxis in predicted severe acute pancreatitis: a randomized, double-blind, placebo-controlled trial. JPEN J Parenter Enteral Nutr 2009;33:444-446.

40. Mirtallo JM, Forbes A, McClave SA, Jensen GL, Waitzberg DL, Davies AR. International consensus guidelines for nutrition therapy in pancreatitis. JPEN J Parenter Enteral Nutr 2012;36:284-291.

41. Working Group IAP/APA Acute Pancreatitis Guidelines. IAP/APA evidence-based guidelines for the management of acute pancreatitis. Pancreatology 2013;13(4 Suppl 2):el-e15.

42. Freeman ML, Werner J, van Santvoort HC, et al. Interventions for necrotizing pancreatitis: summary of a multidisciplinary consensus conference. Pancreas 2012;41:1176-1194.

43. Rau B, Bothe A, Beger HG. Surgical treatment of necrotizing pancreatitis by necrosectomy and closed lavage: changing patient characteristics and outcome in a 19-year, single-center series. Surgery 2005;138:28-39.

44. Connor S, Alexakis N, Raraty MG, et al. Early and late complications after pancreatic necrosectomy. Surgery 2005;137:499-505.

45. Adamson GD, Cuschieri A. Multimedia article. Laparoscopic infracolic necrosectomy for infected pancreatic necrosis. Surg Endosc 2003;17:1675.

46. Parekh D. Laparoscopic-assisted pancreatic necrosectomy: a new surgical option for treatment of severe necrotizing pancreatitis. Arch Surg 2006;141:895-902; discussion 902-903.

47. van Santvoort HC, Besselink MG, Bollen TL, Buskens E, van Ramshorst B, Gooszen HG. Case-matched comparison of the retroperitoneal approach with laparotomy for necrotizing pancreatitis. World J Surg 2007;31:1635-1642.

48. Raraty MG, Halloran CM, Dodd S, et al. Minimal access retroperitoneal pancreatic necrosectomy: improvement in morbidity and mortality with a less invasive approach. Ann Surg 2010;251:787-793.

49. Alsfasser G, Hermeneit S, Rau BM, Klar E. Minimally invasive surgery for pancreatic disease - current status. Dig Surg 2016;33:276-283.

50. van Santvoort HC, Besselink MG, Bakker OJ, et al. A step-up approach or open necrosectomy for necrotizing pancreatitis. N Engl J Med 2010;362:1491-1502.

51. van Grinsven J, van Santvoort HC, Boermeester MA, et al. Timing of catheter drainage in infected necrotizing pancreatitis. Nat Rev Gastroenterol Hepatol 2016;13:306-312.

52. van Baal MC, van Santvoort HC, Bollen TL, Bakker OJ, Besselink MG, Gooszen HG. Systematic review of percutaneous catheter drainage as primary treatment for necrotizing pancreatitis. Br J Surg 2011;98:18-27.

53. Kumar N, Conwell DL, Thompson CC. Direct endoscopic necrosectomy versus step-up approach for walled-off pancreatic necrosis: comparison of clinical outcome and health care utilization. Pancreas 2014;43:1334-1339.

54. Sugimoto M, Sonntag DP, Flint GS, et al. Better outcomes if percutaneous drainage is used early and proactively in the course of necrotizing pancreatitis. J Vasc Interv Radiol 2016;27:418-425.

55. Freeny PC, Hauptmann E, Althaus SJ, Traverso LW, Sinanan M. Percutaneous CT-guided catheter drainage of infected acute necrotizing pancreatitis: techniques and results. AJR Am J Roentgenol 1998;170:969975.

56. van Dijk S, Besselink M. Postponed or immediate drainage of infected necrotizing pancreatitis (POINTER trial) [Internet]. London: BioMed Central; c2015 [updated 2017 Mar 20; cited 2017 Apr 11]. Available from: http://www.isrctn.com/ISRCTN33682933.

57. Baron TH, Thaggard WG, Morgan DE, Stanley RJ. Endoscopic therapy for organized pancreatic necrosis. Gastroenterology 1996;111:755-764.

58. Seewald S, Groth S, Omar S, et al. Aggressive endoscopic therapy for pancreatic necrosis and pancreatic abscess: a new safe and effective treatment algorithm (videos). Gastrointest Endosc 2005;62:92-100.

59. Varadarajulu S, Phadnis MA, Christein JD, Wilcox CM. Multiple transluminal gateway technique for EUS-guided drainage of symptomatic walled-off pancreatic necrosis. Gastrointest Endosc 2011;74:74-80.

60. Ross AS, Irani S, Gan SI, et al. Dual-modality drainage of infected and symptomatic walled-off pancreatic necrosis: long-term clinical outcomes. Gastrointest Endosc 2014;79:929-935.

61. Bang JY, Wilcox CM, Trevino J, et al. Factors impacting treatment outcomes in the endoscopic management of walled-off pancreatic necrosis. J Gastroenterol Hepatol 2013;28:1725-1732.

62. Siddiqui AA, Easler J, Strongin A, et al. Hydrogen peroxide-assisted endoscopic necrosectomy for walled-off pancreatic necrosis: a dual center pilot experience. Dig Dis Sci 2014;59:687-690.

63. Abdelhafez M, Elnegouly M, Hasab Allah MS, Elshazli M, Mikhail HM, Yosry A. Transluminal retroperitoneal endoscopic necrosectomy with the use of hydrogen peroxide and without external irrigation: a novel approach for the treatment of walled-off pancreatic necrosis. Surg Endosc 2013;27:3911-3920.

64. van Brunschot S, van Grinsven J, Voermans RP, et al. Transluminal endoscopic step-up approach versus minimally invasive surgical step-up approach in patients with infected necrotising pancreatitis (TENSION trial): design and rationale of a randomised controlled multicenter trial [ISRCTN09186711]. BMC Gastroenterol 2013;13:161.

65. Bakker OJ, van Santvoort HC, van Brunschot S, et al. Endoscopic transgastric vs surgical necrosectomy for infected necrotizing pancreatitis: a randomized trial. JAMA 2012;307:1053-1061.

66. Yamamoto N, Isayama $\mathrm{H}$, Kawakami H, et al. Preliminary report on a new, fully covered, metal stent designed for the treatment of pancreatic fluid collections. Gastrointest Endosc 2013;77:809-814.

67. Antillon MR, Bechtold ML, Bartalos CR, Marshall JB. Transgastric endoscopic necrosectomy with temporary metallic esophageal stent placement for the treatment of infected pancreatic necrosis (with video). Gastrointest Endosc 2009;69:178-180.

68. Tarantino I, Traina M, Barresi L, Volpes R, Gridelli B. Transgastric plus transduodenal necrosectomy with temporary metal stents placement for treatment of large pancreatic necrosis. Pancreas 2010;39:269-270.

69. Sarkaria S, Sethi A, Rondon C, et al. Pancreatic necrosectomy using covered esophageal stents: a novel approach. J Clin Gastroenterol 2014;48:145-152.

70. Gornals JB, De la Serna-Higuera C, Sánchez-Yague A, Loras C, Sánchez-Cantos AM, Pérez-Miranda M. Endosonography-guided drainage of pancreatic fluid collections with a novel lumen-apposing stent. Surg Endosc 2013;27:1428-1434.

71. Sharaiha RZ, Tyberg A, Khashab MA, et al. Endoscopic therapy with lumen-apposing metal stents is safe and effective for patients with pancreatic walled-off necrosis. Clin Gastroenterol Hepatol 2016;14:17971803.

72. Boumitri C, Parra V, Kedia P, Sharaiha RZ, Kahaleh M. Pancreatic necrosectomy by using a lumen-apposing metal stent. Gastrointest Endosc 2015;81:230-231.

73. Neoptolemos JP, London NJ, Carr-Locke DL. Assessment of main pancreatic duct integrity by endoscopic retrograde pancreatography in patients with acute pancreatitis. Br J Surg 1993;80:94-99.

74. Fabbri C, Luigiano C, Cennamo V, et al. Endoscopic ultrasound-guided transmural drainage of infected pancreatic fluid collections with placement of covered self-expanding metal stents: a case series. Endoscopy 2012;44:429-433.

75. Attam R, Trikudanathan G, Arain M, et al. Endoscopic transluminal drainage and necrosectomy by using a novel, through-the-scope, fully covered, large-bore esophageal metal stent: preliminary experience in 10 patients. Gastrointest Endosc 2014;80:312-318.

76. Shah RJ, Shah JN, Waxman I, et al. Safety and efficacy of endoscopic ultrasound-guided drainage of pancreatic fluid collections with lumen-apposing covered self-expanding metal stents. Clin Gastroenterol Hepatol 2015;13:747-752. 
77. Rinninella E, Kunda R, Dollhopf M, et al. EUS-guided drainage of pancreatic fluid collections using a novel lumen-apposing metal stent on an electrocautery-enhanced delivery system: a large retrospective study (with video). Gastrointest Endosc 2015;82:1039-1046.

78. Jang JW, Kim MH, Oh D, et al. Factors and outcomes associated with pancreatic duct disruption in patients with acute necrotizing pancreatitis. Pancreatology 2016;16:958-965.

79. Lau ST, Simchuk EJ, Kozarek RA, Traverso LW. A pancreatic ductal leak should be sought to direct treatment in patients with acute pancreatitis. Am J Surg 2001;181:411-415.

80. Nealon WH, Bhutani M, Riall TS, Raju G, Ozkan O, Neilan R. A uni- fying concept: pancreatic ductal anatomy both predicts and determines the major complications resulting from pancreatitis. J Am Coll Surg 2009;208:790-799; discussion 799-801.

81. Howard TJ, Moore SA, Saxena R, Matthews DE, Schmidt CM, Wiebke EA. Pancreatic duct strictures are a common cause of recurrent pancreatitis after successful management of pancreatic necrosis. Surgery 2004;136:909-916.

82. Sherman S, Freeman ML, Tarnasky PR, et al. Administration of secretin (RG1068) increases the sensitivity of detection of duct abnormalities by magnetic resonance cholangiopancreatography in patients with pancreatitis. Gastroenterology 2014;147:646-654.e2. 